\title{
The Influence of Winding Location in Flux-Switching Permanent- Magnet Machines
}

\author{
Hengliang Zhang ${ }^{1}$, Wei Hua ${ }^{1}$, Mingjin $\mathrm{Hu}^{1}$, David Gerada ${ }^{2}$, and Chris Gerada ${ }^{2}$ \\ ${ }^{1}$ School of Electrical Engineering, Southeast University, No. 2 Si Pai-lou, Nanjing, 210096, China \\ ${ }^{2}$ Faculty of Engineering, The University of Nottingham, Nottingham, NG7 2RD, UK \\ huawei1978@seu.edu.cn
}

\begin{abstract}
The main purpose of this paper is to investigate the influence of winding location on back electromotive force and armature inductance in flux-switching permanent-magnet machines. To obtain an analytical solution, a double-stator-pitch model is built based on the equivalent magnetic circuit method. Then, the open-circuit characteristics in flux-switching permanent-magnet machines with different winding layouts are analyzed by both the analytical model and finite-element-analysis method. The analysis reveals that winding inductance is easier influenced by the winding location than the permanent-magnet flux linkage and corresponding back electromotive force. Finally, the analytical and finite element predictions are verified by experimental results.
\end{abstract}

Index Terms - flux linkage, winding inductance, flux-switching, PM machine, fractional-slot concentrated winding.

\section{INTRODUCTION}

$\mathrm{D}^{\mathrm{s}}$ UE to the excellent flux-concentrating effect [1], fluxswitching permanent-magnet (FSPM) machines are considered as promising candidates for high power/torque density and high efficiency applications, e.g., electric vehicles (EVs) [2], wind power generation [3], aerospace [4], and so on.

Until now, many research interests have been focused on operation principle [5], optimization [6], and control strategy [7] of FSPM machines. However, the specific manufacturing consideration of FSPM machines is still not reported.

In researching a 10kW FSPM machine for hybrid-electric vehicles (HEVs), the winding location was found to have significant influence on the winding inductance but slight influence on the back electromotive force (EMF). In fact, the winding inductance plays a key role in determining various aspects of the performance of electrical machines [8]. The analysis and calculation of winding inductance in induction machines was introduced in [9]. The winding inductances of brushless permanent magnet (PM) machines are investigated in [8] and [10], where the slot leakage component is found to be the main component of the winding inductance in fractional-slot concentrated-winding (FSCW) PM machines. Further, in [11] the analytical solutions of the slot leakage inductance in FSCW surface-PM machines are derived by solving two-dimensional (2D) Poisson problem associated with the slot region. However, specific investigation on winding inductance in FSPM machines is still not reported.

In this paper, a double-stator-pitch magnetic circuit model of FSPM machines is built in order to reveal the nature of the aforementioned phenomenon. Analytical results are verified by $2 \mathrm{D}$ finite element analysis (FEA). Finally, a prototype FSPM machine is assembled and tested to prove the analysis and prediction.

\section{Winding LAyout, FluX LinKage, AND IndUCTANCE}

Two winding layouts are introduced in this section. Then, the PM flux linkage and winding inductance are derived by a magnetic circuit model (MCM), and verified by 2D-FEA prediction.

\section{A. Winding Layout}

In Fig. 1, two possible winding layouts of FSPM machines are displayed as L-I and L-II, where each slot space is divided in vertical and horizonal directions in L-I and L-II machines respectively, and distributed to two different phase windings.

As a result, in L-I machines all winding coils have the same shape, relative location, and hence the same back-EMF and winding inductance. However, in L-II machines, each winding coil has a different relative location from its adjacent two winding coils. Hence, each two adjacent coils should have different back-EMF and inductance waveforms in L-II FSPM machines. The aforesaid difference will be evaluated in subsequent sections.

In addition, it should be noted that the L-I machines are more difficult to manufacture with higher winding package factor due to the difficulty in reshaping winding coils in circumferential direction over radial direction. Considering the length limitation, only the L-II FSPM machine is investigated to discover the influence of winding location.

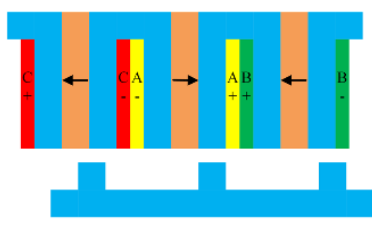

(a)

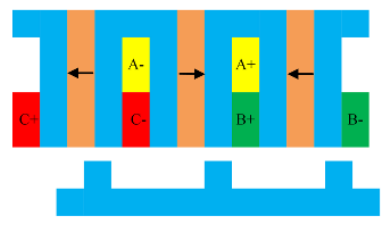

(b)
Fig. 1. Two types of winding layouts of FSPM machines. (a) L-I. (b) L-II

\section{B. Double-Stator-Pitch Magnetic Circuit Model}

In [12], a nonlinear adaptive lumped parameter MCM was developed to predict the electromagnetic performance of FSPM machines, together with the permeance of key magnetic paths. In this paper, a simplification to build the magnetic circuit model only in the double-stator-pitch area is made, and the following assumptions are observed: 1) silicon steel sheets have infinite permeability; 2) magnets have the same permeability as vacuum; 3) no saturation; and 4) no end effect. 
In Fig. 2, main PM magnetic paths of L-II FSPM machines at two typical rotor positions are illustrated, namely the $d$ - and $q$-axis positions. Since it is assumed that silicon steel sheets have infinite permeability and consequently, no saturation is considered, only the magnet-permeance and air-gappermeance marked in orange and purple respectively are taken into account. The corresponding MCMs are shown in Fig. 3.

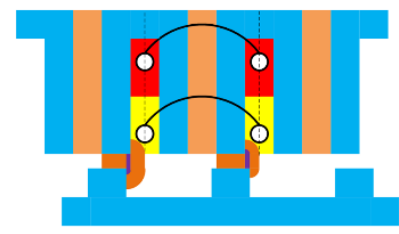

(a)

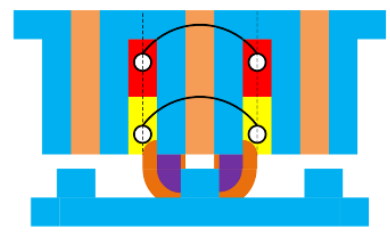

(b)
Fig. 2. $d q$-axes rotor positions in L-II FSPM machines. (a) $d$-axis. (b) $q$-axis.

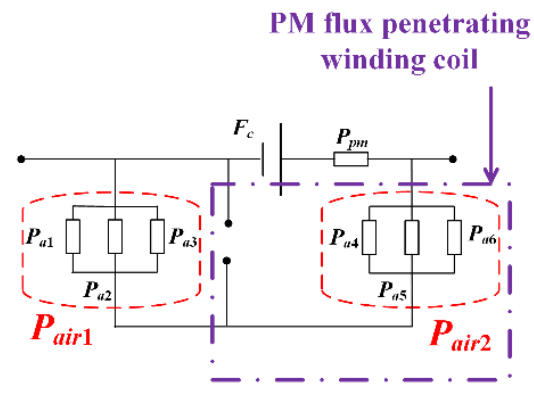

(a)

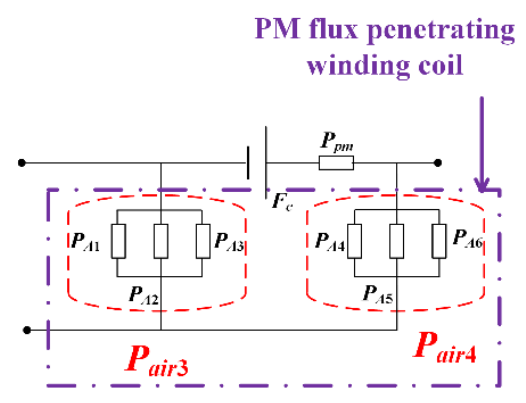

(b)

Fig. 3. Magnetic circuit models at $d q$-axes positions. (a) $d$-axis. (b) $q$-axis.

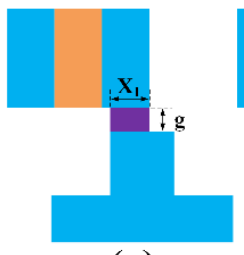

(a)

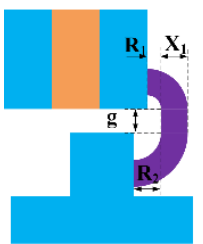

(c)

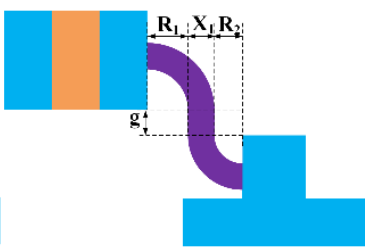

(b)

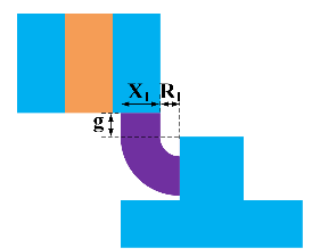

(d)
Fig. 4. Four typical air-gap-permeance. (a) $\mathrm{P}_{1}$. (b) $\mathrm{P}_{2}$. (c) $\mathrm{P}_{3}$. (d) $\mathrm{P}_{4}$.
In [12], [13], typical air-gap-permeances were deduced as in Fig. 4. The four typical air-gap-permences can be calculated by:

$$
\begin{gathered}
P_{1}=\mu_{0} \frac{L X_{1}}{g} \\
P_{2}=2 \mu_{0} \frac{L X_{1}}{\pi\left(R_{1}+R_{2}+X_{1}\right)+2 g} \\
P_{3}=\mu_{0} \frac{L}{\pi} \ln \left(1+\frac{2 \pi X_{1}}{\pi\left(R_{1}+R_{2}\right)+2 g}\right) \\
P_{4}=2 \mu_{0} \frac{L}{\pi} \ln \left(1+\frac{\pi X_{1}}{\pi R_{1}+2 g}\right)
\end{gathered}
$$

where, $P_{1}-P_{4}$ are the typical air-gap-permeances, $L$ is the active stack length, $\mu_{0}$ is the permeability of vacuum, and $g$ is the air-gap length.

\section{PM Flux Linkage}

According to the simple magnetic path model of Fig. 2, the inner and the outer coils (marked in yellow and red respectively) have the same PM flux linkage. Then, based on the MCM in Fig. 3, $d$-axis PM flux linkages in the inner and outer coils can be obtained by:

$$
\begin{gathered}
\psi_{d}=N F_{c} \frac{P_{p m} P_{a i r 1} P_{a i r 2}}{P_{a i r 1} P_{a i r 2}+P_{p m} P_{a i r 1}+P_{p m} P_{a i r 2}} \\
P_{a i r 1}=P_{a 1}+P_{a 2}+P_{a 3} \\
P_{a i r 2}=P_{a 4}+P_{a 5}+P_{a 6}
\end{gathered}
$$

where $N$ is the number of turns per coil, and $F_{c}$ is the PM magneto-motive-force (MMF). For the $q$-axis PM flux linkages in inner and outer coils yield:

$$
\begin{gathered}
\psi_{q}=0 \\
P_{\text {air } 3}=P_{A 1}+P_{A 2}+P_{A 3} \\
P_{\text {air } 4}=P_{A 4}+P_{A 5}+P_{A 6}
\end{gathered}
$$

When the rotor is at the $q$-axis position, the PM flux flows out of the coil through $P_{\text {air }}$ then goes back to the coil through $P_{\text {air } 3}$. Hence, the pure PM flux penetrating the coil is 0 . Based on aforementioned four typical air-gap-permeance calculation formulae and specific geometrical parameters, all air-gappermeance in equations (5)-(10) can be obtained, which are also the basis for calculating the armature flux penetrating the air-gap.

\section{Slot Leakage Inductance}

In FSPM machines, the magnetic paths of armature flux and PM flux are different, which means that although the inner and outer coils have the same PM flux linkage, the winding inductances may be different. As shown in Fig. 5, a clear difference can be observed between the PM magnetic path and the armature magnetic path.

Furthermore, FSPM machines are FSCW-PM machines, where the main component of the winding inductance is the 
slot leakage inductance. From Fig. 5, it can be seen that the slot leakage magnetic path of the inner coil (yellow) is different to that of the outer coil (red). To evaluate this difference, an analytical solution of the slot leakage inductance is derived as follows.

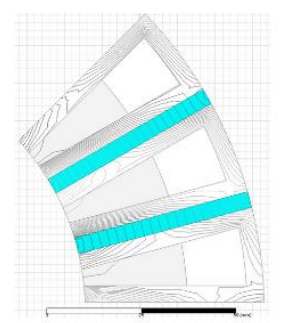

(a)

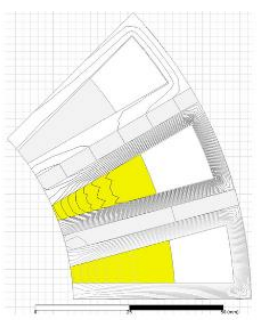

(b)

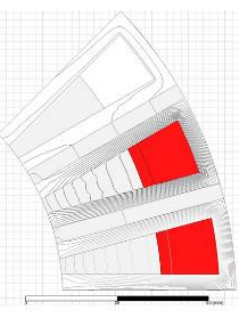

(c)
Fig. 5. Magnetic flux in L-II FSPM machines from 2D-FEA results. (a) PM flux. (b) Armature flux of inner coil. (c) Armature flux of outer coil.

Fig. 6. Tapered slot.

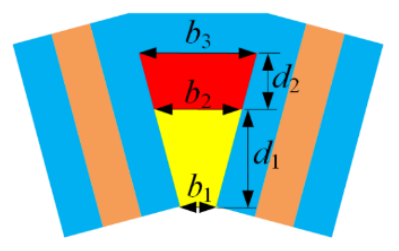

To simplify the derivation, the stator slot is treated as a tapered slot shown in Fig. 6. To ensure inner (yellow) and outer (red) coils have the same turn number, the following constraint should be observed:

$$
d_{1}\left(b_{1}+b_{2}\right)=d_{2}\left(b_{2}+b_{3}\right)
$$

Then, the slot leakage inductance can be calculated using permeance function as follows [9]:

$$
\begin{gathered}
P_{\text {in }}=\mu_{0}\left[\frac{d_{2}}{b_{3}-b_{2}} \ln \left(\frac{b_{3}}{b_{2}}\right)+\frac{d_{1}}{b_{2}} \frac{\beta_{i}^{2}-\frac{\beta_{i}^{4}}{4}-\ln \left(\beta_{i}\right)-\frac{3}{4}}{\left(1-\beta_{i}\right)\left(1-\beta_{i}^{2}\right)^{2}}\right] \\
\beta_{i}=\frac{b_{1}}{b_{2}} \\
P_{\text {out }}=\mu_{0}\left[\frac{d_{1}}{b_{2}-b_{1}} \ln \left(\frac{b_{2}}{b_{1}}\right)+\frac{d_{2}}{b_{3}} \frac{\beta_{o}^{2}-\frac{\beta_{o}^{4}}{4}-\ln \left(\beta_{o}\right)-\frac{3}{4}}{\left(1-\beta_{o}\right)\left(1-\beta_{o}^{2}\right)^{2}}\right] \\
\beta_{o}=\frac{b_{2}}{b_{3}}
\end{gathered}
$$

It should be noted that equations (12) and (14) are for the inner and outer coils respectively. Then, the slot leakage inductance per coil can be obtained from:

$$
\begin{aligned}
L_{\text {slot-incoil }} & =N^{2} L P_{\text {in }} \\
L_{\text {slot-outcoil }} & =N^{2} L P_{\text {out }}
\end{aligned}
$$

The slot leakage inductance per phase is then:

$$
\begin{aligned}
L_{\text {slot-inphase }} & =\frac{2 N_{s}}{m} N^{2} L P_{\text {in }} \\
L_{\text {slot-outphase }} & =\frac{2 N_{s}}{m} N^{2} L P_{\text {out }}
\end{aligned}
$$

where $N_{s}$ is the stator slot number, $m$ is the phase number. The slot leakage inductance of the inner phase and the outer phase are $L_{\text {slot-inphase }}$ and $L_{\text {slot-outphase }}$, respectively.

\section{E. FEA Verification}

To prove the foregoing analysis, a 2D-FEA model of the LII FSPM machine is built in Fig. 7. The key dimensions and the specific slot parameters are listed in Tables I and II, respectively. The prototype is a dual-3-phase L-II FSPM machine for EVs, in which all inner coils are allocated to one 3-phase system (comprised of phases A-C-E) and all outer coils are allocated to another 3-phase system (comprised of phases B-D-F).

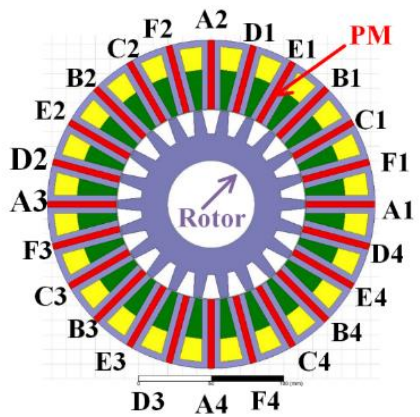

Fig. 7. A dual-3-phase 24-stator-slot/22-rotor-pole FSPM machine.

TABLE I

KEY PARAMETERS OF THE L-II FSPM MACHINE

\begin{tabular}{cc}
\hline \hline Parameter & Value \\
\hline Stator slots number & 24 \\
Rotor pole number & 22 \\
Phase number & 6 (dual-3-phase) \\
Turn number per coil & 28 \\
Magnet material & NdFeB35 \\
Silicon steel sheet & $50 \mathrm{WW} 470$ \\
Stator outer radius & $113 \mathrm{~mm}$ \\
Stack length & $75 \mathrm{~mm}$ \\
Air-gap length & $0.9 \mathrm{~mm}$ \\
Magnet thickness & $4.29 \mathrm{~mm}$ \\
Magnet length & $47.5 \mathrm{~mm}$ \\
Stator inner radius & $65.5 \mathrm{~mm}$ \\
Stator tooth width & $4.29 \mathrm{~mm}$ \\
Rotor outer radius & $64.6 \mathrm{~mm}$ \\
Rotor tooth width & $5.9 \mathrm{~mm}$ \\
Rated speed & $500 \mathrm{r} / \mathrm{min}$ \\
\hline \hline
\end{tabular}

TABLE II

SLOT PARAMETER OF THE L-II FSPM MACHINE

\begin{tabular}{cc}
\hline \hline Parameter & Value \\
\hline$d_{1}$ & $27.2 \mathrm{~mm}$ \\
$d_{2}$ & $15.8 \mathrm{~mm}$ \\
$b_{1}$ & $4.3 \mathrm{~mm}$ \\
$b_{2}$ & $11.4 \mathrm{~mm}$ \\
$b_{3}$ & $15.5 \mathrm{~mm}$ \\
\hline \hline
\end{tabular}


To verify the analytical calculation of PM flux linkage, $d$ and $q$-axis PM flux linkage of a single coil from analytical and FEA results are compared in Table III. It is found that analytical results are a bit different from the FEA predictions due to the stated simplifications in the MCM. However, both the results reveal that inner and outer coils exhibit very close PM flux linkages, which concur with the analysis.

Furthermore, the slot leakage inductances of the inner and outer coils are analytically predicted in Table IV, with the values for the inner and outer coils being $1.81 \mathrm{mH}$ and $2.48 \mathrm{mH}$, respectively, which verifies that inner and outer coils have different values. Then, the average inductance per phase is analytically calculated using slot leakage inductance and armature flux penetrating the air-gap. Both the FEA and analytical results are listed in Table IV. Although some difference exists between the FEA and analytical results, the results are consistent in that the inner and outer coils have different phase inductance. The difference between the analytical and FEA values can be attributed to the simplification of the MCM.

Finally, the open-circuit phase flux linkage, self-inductance, and back-EMF of the L-II FSPM machine @ 500r/min are calculated by the FEA method. As shown in Fig. 8, inner and outer coils have very similar flux linkage waveforms, and only slight ripple is found in their self-inductance waveforms, which means that calculating the average inductance is an effective way to evaluate inductance. From Fig. 9, the phase back-EMF waveforms and harmonic spectra reveal that there is only a small difference (less than $1.5 \%$ ), between the inner and outer coils' induced back-EMFs.

TABLE III

COMPARISON OF D-AXIS PM FLUX LINKAGES

\begin{tabular}{ccc}
\hline \hline PM Flux Linkage & Analytical & FEA \\
\hline$d$-axis PM flux linkage of inner coil & $13.2 \mathrm{mWb}$ & $11 \mathrm{mWb}$ \\
$d$-axis PM flux linkage of outer coil & $13.0 \mathrm{mWb}$ & $11 \mathrm{mWb}$ \\
$q$-axis PM flux linkage of inner coil & $0 \mathrm{mWb}$ & $0 \mathrm{mWb}$ \\
$q$-axis PM flux linkage of outer coil & $0 \mathrm{mWb}$ & $0 \mathrm{mWb}$ \\
\hline \hline
\end{tabular}

TABLE IV

SLOT LEAKAGE INDUCTANCE PER PHASE

\begin{tabular}{cc}
\hline \hline Leakage Inductance & Analytical \\
\hline Inner coil & $1.81 \mathrm{mH}$ \\
Outer coil & $2.48 \mathrm{mH}$ \\
\hline \hline
\end{tabular}

TABLE V

Phase AVERAGE INDUCTANCE

\begin{tabular}{ccc}
\hline \hline Average Inductance & Analytical & FEA \\
\hline Inner coil & $2.61 \mathrm{mH}$ & $2.37 \mathrm{mH}$ \\
Outer coil & $3.28 \mathrm{mH}$ & $3.70 \mathrm{mH}$ \\
\hline \hline
\end{tabular}

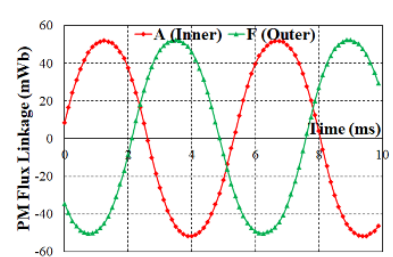

(a)

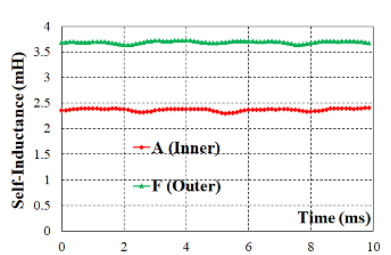

(b)
Fig. 8. Open-circuit phase flux linkage and self-inductance in the dual-3phase FSPM machine @ 500r/min. (a) PM flux linkage. (b) Self-inductance.

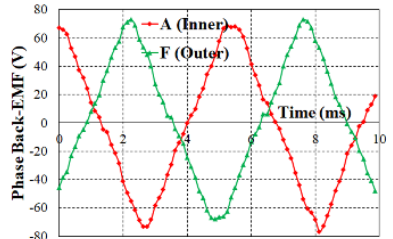

(a)

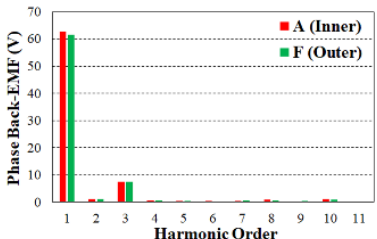

(b)
Fig. 9. Open-circuit phase back-EMF in the dual-3-phase FSPM machine @ 500r/min. (a) Phase back-EMF waveform. (b) Harmonic spectrum.

\section{EXPERIMENTAL VERIFICATION}

In order to verify the analysis, a proposed dual-3-phase L-II FSPM machine was manufactured and tested as shown in Fig. 10. The manufacturing process is as follows: 1 . the silicon steel sheets for the stator are fixed in an aluminum shell using dovetail slot structure; 2 . the silicon steel sheets are cut into specific shapes by using wire-electrode cutting; 3 . the magnets are inserted into the stator; 4 . the outer coils are wound on stator teeth; 5. the inner coils are wound on stator teeth; 6 . assembling the stator and rotor together.

From Fig. 11, it is shown that all winding coils have the similar back-EMF with a fundamental amplitude of around $52 \mathrm{~V} @ 500 \mathrm{r} / \mathrm{min}$. However, the outer coil exhibits a larger self-inductance than the inner one, as shown in Fig. 12. The analytical, FEA, and tested back-EMF and inductance parameters are listed in Table VI. The differences between analytical and FEA results can be attributed to the simplified MCM, whereas the error between FEA and tested results is due to the 3D end-effects and manufacturing errors.

It can be concluded that inner and outer coils have very close fundamental back-EMF values but the outer coil has a higher inductance, with such observations being consistent and in good agreement from the analytical, FEA, and experimental results presented.

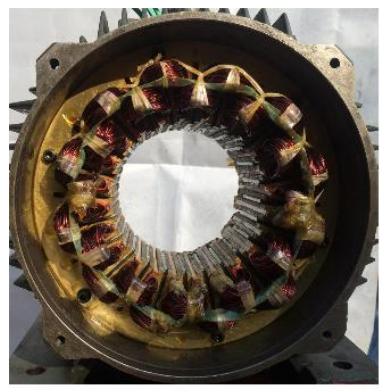

(a)

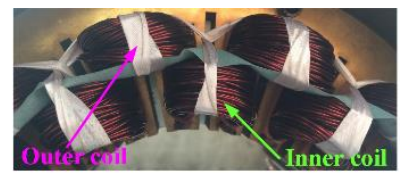

(b)

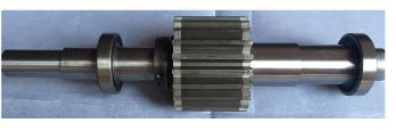

(c)
Fig. 10. The dual 3-phase L-II FSPM prototype machine. (a) Stator and shell. (b) Winding. (c) Rotor and shaft.

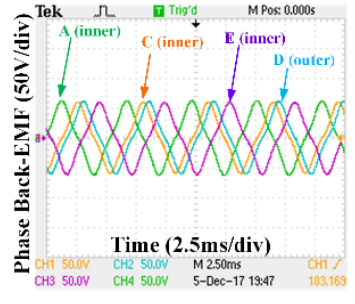

(a)

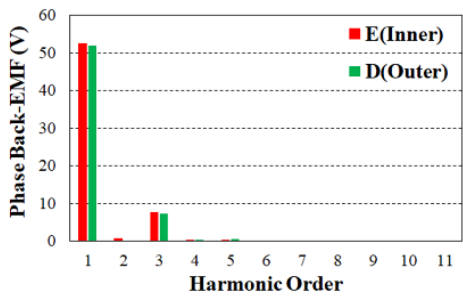

(b)
Fig. 11. Phase back-EMF in dual-3-phase FSPM prototype machine @ 500r/min. (a) Phase back-EMF waveform. (b) Harmonic spectrum. 


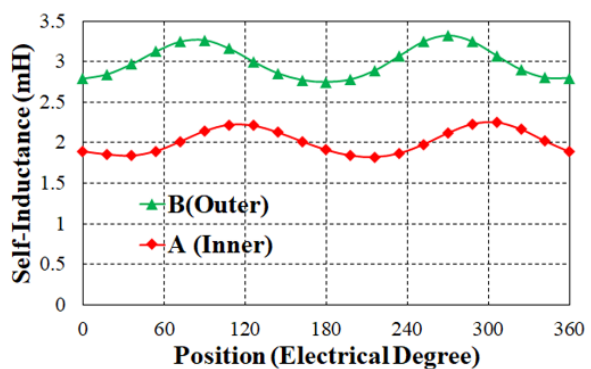

Fig. 12. Self-inductance in dual-3-phase FSPM prototype machine.

TABLE VI

BACK-EMF AND INDUCTANCE PARAMETERS

\begin{tabular}{cccc}
\hline \hline Parameter & Analytical & FEA & Tested \\
\hline Inner back-EMF (fundamental) & $50.7 \mathrm{~V}$ & $62.8 \mathrm{~V}$ & $52.6 \mathrm{~V}$ \\
Outer back-EMF (fundamental) & $50.7 \mathrm{~V}$ & $61.7 \mathrm{~V}$ & $51.4 \mathrm{~V}$ \\
Inner average inductance & $2.61 \mathrm{mH}$ & $2.37 \mathrm{mH}$ & $2.01 \mathrm{mH}$ \\
Outer average inductance & $3.28 \mathrm{mH}$ & $3.70 \mathrm{mH}$ & $3.00 \mathrm{mH}$ \\
\hline \hline
\end{tabular}

\section{CONCLUSION}

In this paper, the influence of winding location on the backEMF and inductance in FSPM machines has been investigated. By building a simple magnetic circuit model and 2D-FEA model, it is found that the winding location slightly affects the PM flux linkage and corresponding back-EMF. However, both the analytical and FEA models reveal that the inner and outer coils in L-II FSPM machines should have different slot leakage inductances. By comparing analytical and FEA results, it is concluded that inner and outer coils in L-II FSPM machines exhibit similar PM flux linkage and corresponding back-EMF but the outer coil achieves a higher self-inductance than the inner coil. Through assembling and testing a prototype machine, the analysis was experimentally verified. In light of this, it is suggested that specific consideration should be taken when designing L-II type FSPM machines and implementing their control.

\section{ACKNOWLEDGEMENT}

This work was supported in part by the National Key Research and Development Program of China under Grant 2017YFB1300902, in part by the National Natural Science Foundation of China under Grant 51777032, and in part by the Scientific Research Foundation of Graduate School of Southeast University under Grant YBJJ1834.

\section{REFERENCES}

[1] W. Hua, M. Cheng, et al., "Analysis and optimization of back-EMF waveform of a flux-switching PM motor," IEEE Trans. Energy Convers. 23(3), pp.727-733, Sep. 2008.

[2] W. Hua, H.L. Zhang, et al., "An outer-rotor flux-switching permanentmagnet-machine with wedge-shaped magnets for in-wheel light traction," IEEE Trans. Ind. Electron., vol.64, no.1, pp. 69-80, Jan. 2017.

[3] L.Y. Shao, W. Hua, et al., "Mathematical modeling of a twelve-phase flux-switching permanent magnet machine for wind power generation," IEEE Trans. Ind. Electron., vol.63, no.1, pp.504-516, Jan. 2015.

[4] A.S. Thomas, Z.Q. Zhu, et al., "Multiphase flux-switching permanentmagnet brushless machine for aerospace application," IEEE Trans. Ind. Appl., vol.45, no.6, pp.1971-1981, Nov. 2009.

[5] Z.Z. Wu, and Z.Q. Zhu, "Analysis of air-gap field modulation and magnetic gearing effects in switched flux permanent magnet machines," IEEE Trans. Magn., vol.51, no.5, May 2015. Article \#:8105012.
[6] X. Zhu, Z. Xiang, et al., "Co-reduction of torque ripple for outer rotor flux-switching PM motor using systematic multi-level design and control schemes," IEEE Trans. Ind. Electron., vol. 64, no. 2, pp. 11021112, Feb. 2017.

[7] M.H. Tong, W. Hua, et al., "Investigation of a vector-controlled fivephase flux-switching permanent-magnet machine drive system," IEEE Trans. Magn., vol.52, no.7, Jul. 2016. Article \#: 8600105.

[8] A.M. EL-Refaie, Z.Q. Zhu, et al., "Winding inductances of fractional slot surface-mounted permanent magnet brushless machines," in Proc. IEEE-IAS 2008, pp.1-8, Alberta, Canada, Oct. 2008.

[9] T.A. Lipo, Introduction to AC Machine Design, Wisconsin Power Electronics Research Center, University of Wisconsin-Madison, 2011.

[10] Z.Q. Zhu, D. Howe, et al., "Magnetic field analysis and inductances of brushless DC machines with surface-mounted magnets and nonoverlapping stator windings," IEEE Trans. Magn., vol.31, no.3, pp. 2115-2118, May 1995.

[11] B. Prieto, M.M. Iturralde, et al., "Analytical calculation of the slot leakage inductance in fractional-slot concentrated-winding machines," IEEE Trans. Ind. Electron., vol.62, no.5, pp.2742-2752, May 2015.

[12] Z.Q. Zhu, Y. Pang, et al., "Analysis of electromagnetic performance of flux-switching permanent-magnet machines by nonlinear adaptive lumped parameter magnetic circuit model," IEEE Trans. Magn., vol.41, no.11, pp.4277-4287, Nov. 2005.

[13] Y Tang, J. J.H. Paulides, et al., "Automated design of DC-excited fluxswitching in-wheel motor using magnetic equivalent circuits," IEEE Trans. Magn., vol.51, no.4, Apr. 2015. Article \#: 8103411. 